\title{
$\mathrm{E} \cdot \mathrm{D} \cdot \mathrm{I} \cdot \mathrm{T} \cdot \mathrm{O} \cdot \mathrm{R} \cdot \mathrm{I} \cdot \mathrm{A} \cdot \mathrm{L}$
}

\section{Why a Journal on Failure Analysis?}

t gives me a great deal of pleasure to provide some background of the development of Practical Failure Analysis. In my 17 year experience at ASM International this is only the second time that I have had opportunity to recommend starting up a new periodical. We are hopeful that as you read about the work done to ascertain the interests and desires of our members you will agree that the periodical has a ready audience. If we are successful in meeting their editorial needs, then the periodical will have a bright future.

About two years ago, as we were looking for opportunities in new product startups, the idea of a periodical on failure analysis was presented for discussion. As we looked at the stated technical interests of our members, we found that nearly half said they were somehow involved in failure analysis. Not only that, but several of our conferences had sessions on failure analysis, training courses in this area had a good track record, as did our book sales for titles that addressed this topic. In total we could identify over 20,000 members and customers who either indicated their interest on their membership form or purchased products that indicated their interest in the topic.

As we further explored the opportunity, we found that there were almost no competing periodicals, and in particular, none that addressed the topic from a materials perspective, or that addressed failure analysis from the practitioner's perspective. As a final step in confirming market interest and receptivity, we held two focus groups of engineers involved in the field to obtain their views. The input that we received confirmed that ASM members involved in this field would welcome a periodical addressing the needs of practitioners.

Over the course of the next few months, a business plan was developed, which received enthusiastic ASM Board approval. Hence, the periodical Practical Failure Analysis was approved for launch. Next came the naming of an editor, an editorial board, and solicitation of manuscripts for the first issue. I'm pleased that Mac Louthan agreed to edit the periodical. He is well known to many of us, and with his combination of professionalism, experience, and a dash of wit, I know he will guide the editorial development in ways that will help Practical Failure Analysis grow and develop.

During the development of concepts for the periodical, the ASM Failure Analysis

Committee has been helpful by providing guidance, advice, and by commenting on the approaches selected. Also, the Board of the International Metallographic Society, an Affiliate Society of ASM, has shown a great deal of interest in contributing as an organization, and in providing a liaison to the editorial board. We have acknowledged their interest and willingness to support the periodical with a cover statement, "in cooperation with the International Metallographic Society.”

I want to acknowledge Bill Fillner, manager, Periodical Publications Development, for the many and varied projects he carried out to help us reach this point. Bill originated many of the concepts and design features, developed the business plans, scoped out marketing approaches, and performed many other tasks relating to the startup and launch of the journal. Also, I want to acknowledge Mary Anne Fleming, manager, Technical Journals and Alloy Phase Diagram Publications, and editor of ASM News. Mary Anne has managed the overall development of the publication, contributing to the initial concept, and guiding the concept into a reality. Both of these valued staff members have contributed greatly to the initiation and launch of Practical Failure Analysis.

It is my heartfelt wish that you, as new readers of this periodical, enjoy the content and will help by subscribing, by providing manuscripts, and by offering your critique to help us improve the content.

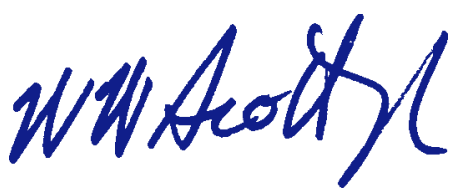

William W. Scott, Jr. Director of Publications ASM International

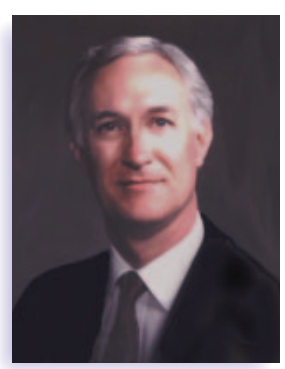

